\title{
Use of anticoagulants in elderly patients: practical recommendations
}

\author{
Helia Robert-Ebadi \\ Grégoire Le Gal \\ Marc Righini
}

Division of Angiology and Hemostasis (HRE, MR), Department of Internal

Medicine, Geneva University Hospital and Faculty of Medicine, Geneva,

Switzerland, and Department of Internal Medicine and Chest Diseases, EA 3878 (GETBO), Brest University Hospital, Brest, France (GLG)
Correspondence: Helia Robert-Ebadi Division of Angiology and Hemostasis, Department of Internal Medicine, Geneva University Hospital and Faculty of Medicine, 24 rue Micheli-du-Crest, $\mathrm{CH}-$ I2II Geneva I4, Switzerland Tel +4I 223729292

$\mathrm{Fax}+4 \mid 223729299$

Email helia.robert-ebadi@hcuge.ch

\begin{abstract}
Elderly people represent a patient population at high thromboembolic risk, but also at high hemorrhagic risk. There is a general tendency among physicians to underuse anticoagulants in the elderly, probably both because of underestimation of thromboembolic risk and overestimation of bleeding risk. The main indications for anticoagulation are venous thromboembolism (VTE) prophylaxis in medical and surgical settings, VTE treatment, atrial fibrillation (AF) and valvular heart disease. Available anticoagulants for VTE prophylaxis and initial treatment of VTE are low molecular weight heparins (LMWH), unfractionated heparin (UFH) or synthetic anti-factor Xa pentasaccharide fondaparinux. For long-term anticoagulation vitamin K antagonists (VKA) are the first choice and only available oral anticoagulants nowadays. Assessing the benefit-risk ratio of anticoagulation is one of the most challenging issues in the individual elderly patient, patients at highest hemorrhagic risk often being those who would have the greatest benefit from anticoagulants. Some specific considerations are of utmost importance when using anticoagulants in the elderly to maximize safety of these treatments, including decreased renal function, co-morbidities and risk of falls, altered pharmacodynamics of anticoagulants especially VKAs, association with antiplatelet agents, patient education. Newer anticoagulants that are currently under study could simplify the management and increase the safety of anticoagulation in the future.
\end{abstract}

Keywords: anticoagulation, elderly patients, venous thromboembolism, hemorrhagic risk, atrial fibrillation, thrombin inhibitors, factor Xa inhibitor

\section{Introduction}

Anticoagulants are one of the most frequently prescribed medications in elderly patients. Indeed, the prevalence of medical conditions representing a risk for thromboembolic complications and requiring antithrombotic therapy increases with age. For instance, the prevalence of atrial fibrillation increases dramatically with age, from $5 \%$ in people aged 65 years and older to approximately $10 \%$ in those over the age of 80 years. ${ }^{1}$ In this review, we will first present the main indications for anticoagulation. Then we will go through the different therapeutic options. Finally, we will emphasize specific important precautions that need to be observed when prescribing anticoagulants in the elderly, and discuss some future perspectives represented by new anticoagulant agents that are currently under study.

\section{Indications for anticoagulation Venous thromboembolism (VTE) prophylaxis}

Incidence rates of VTE increase exponentially with age. ${ }^{2}$ In a recent epidemiological study of hospitalized patients in the United States, the incidence ratios of deep vein thrombosis (DVT) and pulmonary embolism (PE) were of 4.72 (95\% CI 4.30-5.14) and 6.2 (95\% CI 5.74-6.65) in elderly patients ( $\geq 70$ years) compared to younger patients. ${ }^{3}$ This could be partly explained by the fact that the prevalence of comorbidities 
contributing to VTE risk such as malignancy or heart failure increases with age. Also, recovery of full mobility after an acute illness is much slower in the elderly compared to younger adults.

Attempts have been made at defining among elderly medical inpatients higher risk subgroups being most likely to benefit from VTE prophylaxis. Independent risk factors have been identified including restriction of mobility, age $\geq 75$ years, history of DVT or PE, chronic edema of lower limbs, acute heart failure, paresis or paralysis of a lower limb, infectious or rheumatic disease. ${ }^{4,5}$ For surgical patients, the incidence of VTE seems to be more related to the type of surgery and comorbidities (especially malignancy) than to age. It is therefore important that the overall increased risk of VTE in the elderly be taken into account by physicians. The under-use of VTE primary prophylaxis in the elderly seems to be based mainly on fear of a higher bleeding tendency than on facts. ${ }^{6,7}$ As a whole, if some precautions are observed (as will be discussed below), benefits of VTE prophylaxis often outweigh its risks. The Evidence-Based Clinical Practice Guidelines of the American College of Chest Physicians (ACCP) for VTE prophylaxis are summarised in Table $1 .^{8}$

\section{Venous thromboembolism (VTE) treatment}

For patients with objectively confirmed DVT or PE, anticoagulation in the therapeutic range is indicated and should be initiated without delay unless there is an absolute contraindication. Initial treatment consists of low molecular weight heparin (LMWH), the nowadays available synthetic anti-factor Xa pentasaccharide (fondaparinux), or unfractionated heparin
(UFH) in case of severe renal insufficiency, overlapped and followed by an oral vitamin $\mathrm{K}$ antagonist (VKA).

The duration of anticoagulation after a thromboembolic event should be dictated by the balance between protection from VTE recurrence by treatment and hemorrhagic risk on treatment. Recommended duration of anticoagulation varies between guidelines. For VTE associated with transient reversible risk factors (such as trauma or surgery), the latest ACCP guidelines recommend 3 months of anticoagulation. ${ }^{9}$ Indeed, studies conducted in the $1990 \mathrm{~s}$ showed that 3 to 6 months offer a better protection against VTE recurrence than 4 to 6 weeks. ${ }^{10,11}$ In case of recurrent VTE events, long-term anticoagulation is recommended. Schulman et al demonstrated an 18.1\% $(\mathrm{p}<0.001)$ absolute reduction of VTE recurrence rate on long-term versus 6 months of anticoagulation after a second episode of VTE, associated with a non-significant trend for increase in major bleeding after 4 years of follow-up. ${ }^{12}$ In patients with VTE and cancer, LMWH are more effective than VKA. Ideally, LMWH should be the treatment of choice for the initial 3 to 6 months, followed by either VKA or LMWH until the cancer is resolved. ${ }^{9,13}$ More difficult and challenging is to define the duration of anticoagulation in case of unprovoked (also called idiopathic) VTE events and this issue remains a matter of debate. In these patients without any transient risk factor, the ACCP recommends "at least 3 months" of anticoagulation, with all patients being evaluated for risk-benefit ratio of long term oral anticoagulation to prevent recurrent VTE. ${ }^{9}$ This recommendation is somehow difficult to apply in clinical practice. Attempts have been made at identifying risk factors for VTE recurrence using

Table I Levels of venous thromboembolism risk and American College of Chest Physicians recommended thromboprophylaxis in hospitalized patients ${ }^{8}$

\begin{tabular}{lll}
\hline Level of risk & $\begin{array}{l}\text { Approximate DVT risk } \\
\text { without thromboprophylaxis, \% }\end{array}$ & $\begin{array}{l}\text { Suggested thromboprophylaxis } \\
\text { options }\end{array}$ \\
\hline $\begin{array}{l}\text { Low risk } \\
\text { Minor surgery in mobile patients }\end{array}$ & $<10 \%$ & $\begin{array}{l}\text { No specific thromboprophylaxis, } \\
\text { early and aggressive ambulation }\end{array}$ \\
$\begin{array}{l}\text { Medical patients who are fully mobile } \\
\text { Moderate risk }\end{array}$ & $10 \%-40 \%$ & LMWH or low-dose UFH \\
$\begin{array}{l}\text { Most general, open gynecologic } \\
\text { or urologic surgery patients }\end{array}$ & & (bid or tid) or fondaparinux \\
$\begin{array}{l}\text { Medical patients at bed rest or sick } \\
\text { High risk } \\
\text { Hip or knee arthroplasty, hip fracture surgery } \\
\text { Major trauma, spinal cord injury }\end{array}$ & $40 \%-80 \%$ & LMWH or fondaparinux or oral \\
\hline
\end{tabular}

Notes: For patients with moderate or high thromboembolic risk and high bleeding risk, mechanical prophylaxis with intermittent pneumatic compression devices, or venous foot pump and/or graduate compression stockings are recommended.

Abbreviations: DVT, deep vein thrombosis; INR, international normalized ratio; LMWH, low molecular weight heparins; UFH, unfractionated heparin. 
clinical, biological or ultrasonographic characteristics. Some predictive elements include age (HR 1.17 per decade increase), BMI (HR 1.24 per 10 point increase), malignant neoplasm (HR 2.2-4.2), ${ }^{14}$ residual vein thrombosis (HR 2.4), ${ }^{15}$ antiphospholipid antibody syndrome (HR 4.0). ${ }^{16}$ On the other hand, Palareti et al showed that following a first idiopathic DVT, a D-dimer level of $<500 \mu \mathrm{g} / \mathrm{L}$ measured 1 month after discontinuation of anticoagulation was predictive of a low recurrence risk $(6.2 \%$ over 18 months compared to $15 \%$ for patients with D-dimer $>500 \mu \mathrm{g} / \mathrm{L}) .{ }^{17}$ However, this interesting finding does not seem applicable to the elderly in order to identify lower risk patients because the probability of having normal D-dimer level in this population is low. In the absence of a clinical prediction rule, an individual tailoring of treatment is necessary. Anticoagulation is indeed very effective in preventing VTE, with very low recurrence rates of $1.3 \% /$ year $^{16}$ and $2.6 \% / 4$ years $^{12}$ in two studies on long-term anticoagulation, but at the expense of increased bleeding risk. Low-intensity anticoagulation regimens (with a target international normalized ratio [INR] of 1.5-1.9) have thus been studied. They were found to be less efficient than conventional-intensity anticoagulation with an INR of 2.0-3.0 (recurrent VTE rate 1.9/100 patients-years vs 0.7/100 patient-years; HR 2.8) but superior to placebo (recurrent VTE rate 2.6/100 patient-years vs 7.2/100 patient-years, HR 0.36). ${ }^{18,19}$ Although hemorrhagic risk was comparable in low-intensity and conventional-intensity regimen groups in the study by Kearon et $\mathrm{al}^{18}$ the bleeding rates in this study were extremely low in both groups (and different from the usual bleeding rates mentioned in other studies) and probably not representative of real clinical practice. Therefore, in patients with significant hemorrhagic risk in whom long term anticoagulation is considered because of estimated high VTE recurrence risk, reducing intensity to an INR of 1.5 to 1.9 (after the initial 3 months of anticoagulation with a target INR of 2.0-3.0) could represent an option in order to reduce bleeding risk while maintaining some protective effect against VTE recurrence.

\section{Atrial fibrillation (AF)}

The prevalence of atrial fibrillation (AF) increases dramatically with age, reaching approximately $10 \%$ in people over 80 years of age. ${ }^{1}$ Atrial fibrillation is responsible for $15 \%$ of ischemic strokes in the US. ${ }^{20}$ Among AF patients who are not on anticoagulant treatment, the incidence of ischemic stroke is about $4.5 \%$ per year, decreasing to $1.4 \%$ in patients who are on adjusted-dose VKA (NNT = 32). ${ }^{21}$ Several risk stratification schemes have been proposed to identify AF patients at high thromboembolic risk. A recent work by Fang et al compared five risk stratification schemes applied to the ATRIA (AnTicoagulation and Risk Factors In Atrial Fibrillation) study cohort. The authors concluded that all schemes had discriminatory ability to predict thromboembolism, but the ability was relatively low for all. ${ }^{22}$ However, in the absence of more powerful schemes, the widely used CHADS2 score (Table 2) remains a very useful tool in daily practice for stratifying the risk of thromboembolic complications in elderly patients with nonvalvular AF, especially when assessing the risk-benefit ratio of anticoagulation. Furthermore, this score has been validated prospectively in a cohort of 1733 patients aged 65 to 95 years. $^{23}$ The ACCP Evidence-Based Clinical Practice Guidelines for antithrombotic therapy in AF are summarised in Table $3 .^{24}$

\section{Valvular heart disease}

Indication for long-term anticoagulation is well established for prosthetic heart valves because of the high risk of systemic embolism. This is illustrated by an annual incidence of thromboembolic events for St Jude prosthetic heart valves of $12 \%$ for the aortic position and $22 \%$ for the mitral position. ${ }^{25}$ The latest ACCP guidelines recommend anticoagulation with a VKA for all mechanical valves. The target INR for tilting disk or bileaflet valves is $2.5(2.0-3.0)$ in the aortic position and $3.0(2.5-3.5)$ in the mitral position. Because of the higher thromboembolic risk associated with caged ball (Starr) or caged disk prosthetic valves, the recommended target INR is $3.0(2.5-3.5)$ for these valves. In the presence of additional risk factors (such as AF, hypercoagulable state, low ejection fraction, left atrial enlargement), a target INR of $3.0(2.5-3.5)$ is recommended, as well as addition of low dose aspirin (50-100 mg/day). ${ }^{26}$

Table 2 Risk of stroke in the National Registry of Atrial Fibrillation (NRAF) participants, stratified by CHADS2 score ${ }^{23}$

\begin{tabular}{ll}
\hline CHADS2 score $^{\mathrm{a}}$ & $\begin{array}{l}\text { Adjusted stroke rate per } \\
\mathbf{1 0 0} \text { patient-years } \mathbf{( 9 5 \%} \mathbf{C I})\end{array}$ \\
\hline 0 & $1.9(1.2-3.0)$ \\
1 & $2.8(2.0-3.8)$ \\
2 & $4.0(3.1-5.1)$ \\
3 & $5.9(4.6-7.3)$ \\
4 & $8.5(6.3-11.1)$ \\
5 & $12.5(8.2-17.5)$ \\
6 & $18.2(10.5-27.4)$ \\
\hline${ }^{2}$ CHADS2 score is calculated by adding I point for each of the following: recent \\
congestive heart failure, hypertension, age $\geq 75$ years, diabetes mellitus; and 2 points \\
for prior stroke or transient ischemic attack.
\end{tabular}


Table 3 Antithrombotic therapy in nonvalvular atrial fibrillation: American College of Chest Physicians recommendations ${ }^{24}$

\begin{tabular}{|c|c|c|}
\hline Risk categories & $\begin{array}{l}\text { Antithrombotic } \\
\text { recommendation }\end{array}$ & Grade $^{b}$ \\
\hline \multicolumn{3}{|l|}{ High risk } \\
\hline $\begin{array}{l}\text { Chronic or paroxysmal AF, with prior } \\
\text { ischemic stroke, TIA or systemic embolism }\end{array}$ & $\begin{array}{l}\text { Long-term VKA } \\
\text { INR } 2.5(2.0-3.0)\end{array}$ & IA \\
\hline $\begin{array}{l}\text { Chronic or paroxysmal AF } \\
\text { and } \geq 2 \text { risk factors }{ }^{\mathrm{a}}\end{array}$ & Long-term VKA INR 2.5 (2.0-3.0) & IA \\
\hline \multicolumn{3}{|l|}{ Intermediate risk } \\
\hline \multirow[t]{3}{*}{ and I risk factor* } & $\begin{array}{l}\text { Long-term VKA INR } 2.5 \text { (2.0-3.0) } \\
\text { or }\end{array}$ & IA \\
\hline & Aspirin $75-325$ mg/day & IB \\
\hline & VKA preferred to aspirin & $2 \mathrm{~A}$ \\
\hline \multicolumn{3}{|l|}{ Low risk } \\
\hline $\begin{array}{l}\text { Chronic or paroxysmal AF } \\
\text { and age } \leq 75 \text { years and no risk factors }{ }^{\mathrm{a}}\end{array}$ & Long-term aspirin $75-325 \mathrm{mg} /$ day & IB \\
\hline
\end{tabular}

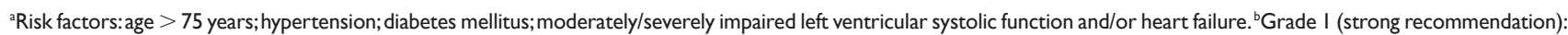
guideline developers are very certain that benefits do outweigh risks, burden and costs. Grade 2 (weaker recommendation): guideline developers are less certain of the magnitude of benefits and risks, burden and costs. Support for these recommendations comes from high-quality, moderate-quality or low-quality evidence (labelled A, B and C). ${ }^{74}$

Abbreviations: AF, atrial fibrillation; TIA, transient ischemic attack; VKA, vitamin $k$ antagonists.

\section{Prophylactic and therapeutic options}

Anticoagulant options for VTE prophylaxis include unfractionated heparin (UFH), low molecular weight heparins (LMWH) and the synthetic anti-factor Xa pentasaccharide (fondaparinux). For therapeutic range anticoagulation, especially long-term anticoagulation, the first and until now only choice consists of vitamin $\mathrm{K}$ antagonists (VKA) because of their oral route of administration.

\section{VTE prophylaxis in medical settings}

Many trials have evaluated safety and efficacy of different therapeutic agents for thromboprophylaxis in medical and surgical patients. In the MEDENOX trial, enoxaparin $40 \mathrm{mg}$ was shown to be superior to placebo in acutely ill medical patients with a reduction of symptomatic VTE and venographically diagnosed asymptomatic DVT from $14.9 \%$ to $5.5 \%(\mathrm{NNT}=11)$ without increasing the risk of adverse events. Enoxaparin $20 \mathrm{mg}$ did not show any difference when compared to placebo in the same study. ${ }^{27}$ As demonstrated in a subgroup analysis of the MEDENOX study, patients over 75 years old (approximately $50 \%$ of the MEDENOX study population) had even a greater benefit from enoxaparin $40 \mathrm{mg}$ with a reduction of VTE risk from $18.5 \%$ to $4.1 \%(\mathrm{NNT}=7) .{ }^{5}$ Comparable efficacy of enoxaparin $40 \mathrm{mg}$ with UFH 5000 IU three times daily in preventing VTE in medical patients with heart failure or severe respiratory disease has also been demonstrated in a study in which more than $55 \%$ of patients were $>70$ years old..$^{28}$ Another LMWH, dalteparin at once daily subcutaneous (sc) dose of 5000 IU was shown to be superior to placebo in medical inpatients in the PREVENT study with a reduction of the incidence of symptomatic VTE and asymptomatic proximal DVT from $4.96 \%$ to $2.77 \%$ $(\mathrm{NNT}=45) .{ }^{29}$ VTE rate in this study was much lower than in MEDENOX because of the difference in definition of the composite primary endpoint (only symptomatic events and asymptomatic proximal DVTs were taken into account in PREVENT). A subgroup analysis of the PREVENT study performed on patients $>75$ years (33.3\% of the study population) showed incidence rates of the same composite endpoint of $4.2 \%$ vs $8.0 \%$ respectively for patients on dalteparin vs placebo $(\mathrm{NNT}=26)$ without increasing the risk of major hemorrage $(1.1 \%$ vs $0.7 \% ; p=0.12){ }^{30}$

The selective inhibitor of factor Xa fondaparinux at once daily sc dose of $2.5 \mathrm{mg}$ has also been shown to be effective and safe in preventing VTE in medical inpatients $>60$ years old. The incidence of VTE (composite endpoint of DVT diagnosed by routine venography and symptomatic VTE) was reduced from $10.5 \%$ in the placebo group to $5.6 \%$ in the fondaparinux group $(\mathrm{NNT}=20) .{ }^{31}$

\section{VTE prophylaxis in surgical settings}

For prevention of VTE following major orthopedic surgery, LMWH are effective and safe as well as fondaparinux. ${ }^{8,32,33}$ The latter is thought to be more effective than LMWH but may be associated with a slightly higher incidence of major bleeds, mainly at surgical site. ${ }^{34,35}$ In case of extended thromboprophylaxis (which is suggested for at least 10 days and up to 35 days after total hip replacement or total knee 
replacement) vitamin $\mathrm{K}$ antagonists with a target INR of 2.0 to 3.0 are an alternative. ${ }^{8}$

In general, for VTE prophylaxis LMWH and fondaparinux should be preferred to UFH whenever possible because of lower risk of heparin-induced thrombocytopenia (HIT) with LMWH and virtually no risk of HIT with fondaparinux (see below).

\section{VTE treatment}

The objectives of anticoagulant therapy in established VTE are prevention of thrombus extension, VTE recurrence (early and late) and post-thrombotic syndrome. Anticoagulation should therefore be started promptly when VTE diagnosis is established, or even before diagnosis confirmation when clinical probability is high. There are several options for the initial treatment of VTE: subcutaneous (sc) LMWH, sc fondaparinux, intravenous (iv) or sc UFH with monitoring, or weight-based sc UFH without monitoring. ${ }^{36}$ In a recent systematic review comparing weight-adjusted fixed dose sc LMWH to adjusted iv UFH, LMWH were associated with fewer thrombotic complications (3.6\% versus 5.4\%), less major bleeding $(1.2 \%$ versus $2.0 \%)$ and lower rate of death $(4.5 \%$ versus $6.0 \%)$, all results being statistically significant. ${ }^{37}$ However, LMWH dose adjustment and laboratory monitoring are needed in patients with renal failure as will be discussed below.

Fondaparinux has also been evaluated for initial treatment of VTE in the Matisse trials. The Matisse DVT study ${ }^{38}$ compared with a double-blinded design once daily sc fondaparinux $7.5 \mathrm{mg}$ (5.0 mg in patients weighing $<50 \mathrm{~kg}$ and $10.0 \mathrm{mg}$ in patients weighing $>100 \mathrm{~kg}$ ) to twice daily sc enoxaparin $1 \mathrm{mg} / \mathrm{kg}$ given for at least 5 days and until an INR greater than 2.0 was reached by VKA. There were no differences in the incidence of symptomatic recurrent VTE (3.9\% for fondaparinux versus $4.1 \%$ for enoxaparin), major bleeding $(1.1 \%$ versus $1.2 \%)$ or death $(3.8 \%$ vs $3.0 \%)$ between the 2 groups during the 3 -month study period. The Matisse PE study ${ }^{39}$ compared with an open-label design once daily sc fondaparinux $7.5 \mathrm{mg}$ to continuous iv UFH (with a target activated partial-thromboplastin time to control value of 1.5-2.5) given for at least 5 days and until an INR greater than 2.0 was reached by VKA. Again, there were no significant differences in rates of symptomatic recurrent VTE $(3.8 \%$ vs $5.0 \%)$, major bleeding (1.3\% versus $1.1 \%$ ) or death $(5.2 \%$ versus $4.4 \%)$. Mean age of patients in these two studies was between 61 and 63 years old \pm 16 , and patients with a serum creatinine level above $177 \mathrm{umol} / \mathrm{L}(2.0 \mathrm{mg} / \mathrm{dL})$ were excluded, so these results may not be directly applicable without specific precautions in the elderly (see below).
Why should we use fondaparinux instead of LMWH? Two elements can be pointed out. First, the risk of HIT with fondaparinux approaches zero, with only one case-report, ${ }^{40}$ and therefore, monitoring of platelets is not recommended. It has even become one of the few recommended molecules for the treatment of HIT (grade IIC), based on the absence of cross-reaction with heparin-PF4 antibodies and clinical experience. ${ }^{41,42}$ Furthermore, this molecule is synthesized, in comparison to UFH or LMWH that are extracted from animal tissue. Although no infectious contamination has ever been described, this could be viewed as an advantage, especially in regard to the numerous anaphylactoid reactions due to the contamination of heparin by chondroin sulphate in heparin in $2008 .{ }^{43}$ Like other anticoagulants, bleeding is the most common serious complication of fondaparinux, and this could be a potential limit in elderly patients, in particular as no antidote exists. However, in case of major bleeding, most authors recommend the use of recombinant factor VIIa, which can reverse the anticoagulant effect in healthy volunteers. ${ }^{44}$

Idraparinux is another synthetic pentasaccharide that indirectly inhibits factor Xa. It differs from fondaparinux in its substantially longer half-life, with a $2.5 \mathrm{mg}$ weekly sc dose in studies, and seemed promising in phase II studies. The Van Gogh Investigators published two randomized open-label noninferiority trials in 2007 that compared the efficacy and safety of 3 to 6 months idraparinux to standard therapy (UFH or LMWH followed by VKA) in patients with DVT and PE. ${ }^{45}$ Although the results satisfied the prespecified non-inferiority requirement in the DVT study, idraparinux proved to be less efficient in PE patients: recurrent VTE was higher in the idraparinux group than in the standard treatment group at 3 months (3.4\% versus $1.6 \%)$ and 6 months (4.0\% versus $2.0 \%$ ). Valid explanations for the difference of efficacy of idraparinux after a DVT and a PE are difficult to formulate. One hypothesis suggests that the early treatment with a long half-life drug and no charging dose could not cover the higher early recurrence risk after PE.

Whichever parenteral anticoagulant is chosen for the initial treatment of VTE, vitamin $\mathrm{K}$ antagonists should be started on the same day. The parenteral agent can then be discontinued after 5 days, provided the INR is $\geq 2.0$ for at least 24 hours. $^{9}$

\section{Atrial fibrillation and valvular heart disease}

As patients with AF or valvular heart disease have an indication for anticoagulation on a long term basis, oral 
vitamin $\mathrm{K}$ antagonists are the drug of choice, and warfarin is the molecule used in most clinical trials in these patients. A recent study compared warfarin with a target INR of 2.0 to 3.0 to aspirin $75 \mathrm{mg}$ /day for stroke prevention in elderly patients. ${ }^{46}$ Patients in this study were $\geq 75$ years with a mean age of 81.5 years \pm 4.2 years. The primary endpoint was a composite of fatal or disabling stroke (ischemic or hemorrhagic), intracranial hemorrhage or clinically significant systemic embolism. Analysis was performed on an intention-to-treat basis. The yearly incidence of the primary endpoint was $1.8 \%$ in the warfarin group and $3.8 \%$ in the aspirin group (RR $0.48,95 \%$ CI $0.28-0.80, p=0.003$ ). The incidence of ischemic stroke was $0.8 \%$ versus $2.5 \%$ (RR $0.30,95 \%$ CI $0.13-0.63, \mathrm{p}=0.0004)$ and hemorrhagic stroke $0.5 \%$ versus $0.4 \%$ (RR $1.15,95 \%$ CI $0.29-4.77, \mathrm{p}=0.83$ ). The effect of crossovers between the two groups in this study may have altered the results concerning hemorrhagic risk, but this effect was estimated to be small by the authors as there were no differences in either intention-to-treat or on-treatment analyses.

Overall, anticoagulation is considered to be more effective than aspirin in elderly patients with AF in preventing stroke, provided there are no contraindications to anticoagulation and the patient decides that benefits are worth the inconvenience of long term oral anticoagulation.

\section{Special considerations when prescribing anticoagulants in the elderly \\ Hemorrhagic risk}

Bleeding is the major complication of anticoagulants. The risk of bleeding is dependent on many factors including intensity of anticoagulation and patient's intrinsic characteristics. For anticoagulation in the therapeutic range, patient's age represents an independent risk factor for bleeding with all anticoagulation modalities. ${ }^{47}$

\section{UFH}

In their study on UFH for initial treatment of DVT, Campbell et al showed an increased rate of bleeding and major bleeding in patients $\geq 72$ years, compared with those under 72 years (14.1\% versus $7.1 \%$ for bleeding and $11.1 \%$ versus $3.1 \%$ for major bleeding) ${ }^{48}$ They also observed that elderly patients required lower doses of heparin to achieve therapeutic aPTT levels, and had higher plasma heparin levels at standard doses of UFH (not adjusted to weight). Factors believed to alter pharmacodynamics of heparins in elderly include changes in coagulation factors with age, body weight and composition. Furthermore, in addition to binding to antithrombin to achieve their anticoagulant effect, heparins bind to numerous other plasma proteins and cellular components. The variability of these determinants of heparins' distribution volume also contributes to the variability of response among patients. ${ }^{49}$ To minimize risks of overanticoagulation with UFH, it is recommended to use a weight-adjusted dosing pattern. For initial treatment of VTE, an initial iv bolus of $80 \mathrm{IU} /$ $\mathrm{kg}$ is recommended followed by a continuous infusion at $18 \mathrm{IU} / \mathrm{kg} / \mathrm{h} .{ }^{9}$ Then, the dose should be adjusted according to aPTT level (target aPTT ratio of 1.5-2.5).

\section{LMWH and fondaparinux}

As already mentioned above, LMWH should be preferred to UFH not only because of much lower rates of heparininduced thrombocytopenia, but also because of overall lower bleeding risk. In the Cochrane Database systematic review mentioned above, van Dongen et al demonstrated a significantly lower risk of major bleeding with LMWH than with UFH (1.2\% versus $2.0 \%$ ) when used in VTE treatment. ${ }^{37}$ This could be explained by higher bioavailability and more predictable anticoagulant response of LMWH compared to UFH due to their lesser avidity of binding to plasma proteins. ${ }^{49}$ Fondaparinux was shown to be associated with higher risk of major bleeding at prophylactic dose of $2.5 \mathrm{mg} /$ day than enoxaparin (40 mg/day or twice daily $30 \mathrm{mg}$ ) in major orthopedic surgery $(2.7 \%$ versus $1.7 \%)$ in the meta-analysis by Turpie et al but this difference was mainly attributed to surgical site bleeding. ${ }^{34}$ In Matisse trials, at therapeutic dose of $7.5 \mathrm{mg} /$ day, bleeding risk of fondaparinux was comparable with therapeutic doses of UFH or LMWH (major bleeding rate of $1.1 \%-1.3 \%$ for all three substances). ${ }^{38,39}$

In elderly patients, to avoid excessive anticoagulation with LMWH/fondaparinux and reduce bleeding risk, special attention should be given to assessing renal function before prescribing LMWH and fondaparinux as will be discussed below.

\section{VKA}

Warfarin is currently the most extensively prescribed oral anticoagulant agent world-wide. The fear of bleeding complications is a major concern, and the narrow therapeutic range, individual variable dose-response and numerous interactions with other medications can represent challenges in maintaining a safe and stable level of anticoagulation with VKA. Some of the determinants of anticoagulant response which have clinical relevance in the elderly will be discussed later in this section. 
In clinical studies with careful monitoring of anticoagulant intensity, treatment with VKA increases the risk of major bleeding by 0.3 to $0.5 \%$ year and the risk of intracranial hemorrhage by $0.2 \%$ /year compared to patients without VKA. However, higher (but variable) rates have been reported in patients on VKA in clinical routine practice, especially in the elderly. ${ }^{47}$ Fang et al showed an increased risk of major hemorrhage, particularly intracranial hemorrhage (ICH) in patients with $\mathrm{AF} \geq 80$ years whether or not they were on warfarin. Although patients on warfarin in this observational study may have been represented by low bleeding risk patients, the authors concluded that carefully monitored anticoagulation with warfarin could be used with safety in elderly patients. ${ }^{50}$ Palareti et al also showed only a tendency toward increased overall bleeding on warfarin (prescribed for several different indications) in patients $\geq 75$ years compared to those $<70$ years $(9.9 \%$ vs $6.6 \% ; \mathrm{p}=0.7)$, but a significant increase in the risk of intracranial hemorrhage $(1.1 \%$ vs $0.2 \%$, $\mathrm{p}=0.05$ ) with age.$^{51}$ Hylek et al showed higher rates of major hemorrhage on warfarin in patients $\geq 80$ years compared with those $<80$ years (13.1 vs 4.7 per 100 patient-years) during the first year of warfarin therapy, the bleeding rates being highest during the first 3 months of anticoagulation. ${ }^{52}$ These higher rates compared to previous studies can be explained by patients' older age and especially by the fact that the majority of patients in other studies were already on warfarin before getting included in the studies, therefore representing a pre-selected group of "warfarin-tolerant" patients. To better assess the hemorrhagic risk during the first three months of anticoagulation, Ruiz-Gimenez et al developed a simple bleeding score based on 6 clinical or biological items: history of recent bleeding, creatinine, anemia, cancer, clinical PE, age $>75$ years (Table 4 ). ${ }^{53}$ It identified $20 \%$ of patients at very low risk of bleeding $(0.1 \%-0.3 \%)$ at 3 months, and another $5 \%$ at high risk ( $>6 \%$ at 3 months). However, this score has not been validated in a prospective study, and does not evaluate the bleeding risk after 3 months.

One of the major determinants of bleeding associated with VKA is the intensity of anticoagulant effect, the risk of major bleeding in patients with INR $>3.0$ being more than double the risk of patients with INR between 2.0 and 3.0. ${ }^{47}$ In a case-control study, Fang et al identified an increased risk of ICH in patients with an INR of 3.5 to 3.9 compared to those with an INR between 2.0 and 3.0 (adjusted odds ratio 4.5 ; 95\% CI 2.3-9.4). ${ }^{54}$ In the above-mentioned study by Palareti et al increased bleeding risk with supratherapeutic INR was also demonstrated, with an exponential increase for INR values $>4.5$ in both age categories. ${ }^{51}$ In these two latter studies, the risk of ICH was not different between patients with an INR $<2.0$ and patients with an INR of 2.0 to 3.0, suggesting that well controlled oral anticoagulation does not carry a high hemorrhagic risk.

Thus, whenever prescribing oral anticoagulation is decided in elderly patients, special attention should be given to avoid over-anticoagulation to minimise hemorrhagic complications. The benefit in terms of bleeding risk in reducing anticoagulant intensity is not widely accepted, and target INR should be the same as in younger patients (2.0-3.0 for almost all indications).

Some authors believe there is a tendency among physicians to overestimate bleeding risk in elderly patients who would be candidates for anticoagulation for AF. One of the postulated reasons is that physicians in general feel personally responsible for a hemorrhagic complication of anticoagulant treatment, as opposed to a thromboembolic complication because of absence of treatment. ${ }^{55}$ Classification scores have been developed to help physicians assess hemorrhagic risk on VKA in individual patients. The HEMORR2HAGES score

Table 4 The RIETE Registry bleeding score ${ }^{53}$

\begin{tabular}{|c|c|c|c|}
\hline Risk factors & Score & & \\
\hline Recent major bleeding & 2 points & & \\
\hline Creatinine level $>1.2 \mathrm{mg} / \mathrm{dL}(110 \mu \mathrm{mol} / \mathrm{L})$ & 1.5 points & & \\
\hline Anemia $(\mathrm{Hb}<13$ (men) or 12 (women) g/dL) & 1.5 points & & \\
\hline Cancer & I point & & \\
\hline Clinically overt PE & I point & & \\
\hline Age $>75$ years & I point & & \\
\hline \multicolumn{4}{|c|}{ Rate of major bleeding per 100 patients within 3 months of anticoagulant therapy according to the score: } \\
\hline Score & 0 & $1-4$ & $>4$ \\
\hline Rate $(\%, 95 \% \mathrm{Cl})$ & $0.3(0.1-0.6)$ & $2.6(2.3-2.9)$ & $7.3(5.6-9.3)$ \\
\hline
\end{tabular}


developed by Gage et $\mathrm{al}^{56}$ takes the following bleeding risk factors into account: Hepatic or renal disease, Ethanol abuse, Malignancy, Older age ( $>75$ years), Reduced platelet count or function, Rebleeding risk, Hypertension (uncontrolled), Anemia, Genetic factors, Excessive fall risk, and Stroke, giving 1 point to each item apart from Rebleeding risk which gets 2 points. The annual incidence of major bleeding according to this score is presented in Table 5. Another bleeding risk model was also developed for elderly warfarin recipients taking into account eight items: age $\geq 70$ years, gender, remote bleeding, recent bleeding, alcohol/drug abuse, diabetes, anemia, antiplatelet use. All patients in this latter study were $>65$ years old and $43 \%$ were $\geq 80$ years. The rate of major bleeding was $0.9 \%, 2.0 \%$ and $5.4 \%$ for groups with low, moderate and high risk. ${ }^{57}$

One of the major difficulties concerning anticoagulation in elderly patients is that those at highest risk for bleeding are those who would have highest benefit from anticoagulation. Thromboembolic and hemorrhagic prediction scores can help physicians balance the risk-benefit ratio for anticoagulation in individual patients. Patient's preferences should also always be taken into account.

\section{Decreased renal function}

Renal function decreases gradually with age. As LMWHs and fondaparinux are cleared in the urine, assessing renal function is of upmost importance when prescribing these anticoagulants in the elderly. There is not enough evidence in the literature for defining an optimal creatinine clearance cut-off under which LMWH should be contra-indicated. ${ }^{58}$ Mahe et al assessed the influence of renal function on antifactor Xa activity level at prophylactic doses of enoxaparin

Table 5 Risk of major bleeding on warfarin therapy for AF as stratified by HEMORR2HAGES score ${ }^{56}$

\begin{tabular}{ll}
\hline $\begin{array}{l}\text { HEMORR2HAGES } \\
\text { score }^{\text {a }}\end{array}$ & $\begin{array}{l}\text { Major bleeding per I00 } \\
\text { person-years }(95 \% \mathbf{C I})\end{array}$ \\
\hline 0 & $1.9(0.6-4.4)$ \\
1 & $2.5(1.3-4.3)$ \\
2 & $5.3(3.4-8.1)$ \\
3 & $8.4(4.9-13.6)$ \\
4 & $10.4(5.1-18.9)$ \\
$\geq 5$ & $12.3(5.8-23.1)$ \\
Any score & $4.9(3.9-6.3)$ \\
\hline
\end{tabular}

aHEMORR2HAGES score is calculated by adding I point for each of the following: Hepatic or renal disease, Ethanol abuse, Malignancy, Older age ( $>75$ years), Reduced platelet count or function, Rebleeding risk (2 points), Hypertension (uncontrolled), Anemia, Genetic factors, Excessive fall risk, and Stroke. (once daily sc $40 \mathrm{mg}$ ) in 125 acutely ill elderly medical inpatients (mean age 87.5 years \pm 6.3 years). Creatinine clearance of $<30 \mathrm{~mL} / \mathrm{min}$ and body weight $<50 \mathrm{~kg}$ were associated with significantly higher anti-factor Xa levels. ${ }^{59}$ However, among patients who had serious bleeding in this study (5 patients), anti-factor Xa levels were not higher than in patients without bleeding. Although no clinically relevant conclusion can be drawn from this study, it seems wise to monitor anti-factor Xa level in patients with severely decreased renal function even with prophylactic doses of LMWH to ensure there is no accumulation.

When treating elderly patients with therapeutic doses of LMWH, it is important to keep in mind that even mild decreases in creatinine clearance can lead to accumulation of LMWHs. Mismetti et al administered daily sc nadroparin at 180 anti-Xa IU/kg for 6 to 10 days to healthy young (mean age $25 \pm 4$ ) and elderly (mean age $65 \pm 3$ ) volunteers. Body weight was similar in both groups. The authors demonstrated a significant accumulation of anti-factor Xa activity in the elderly group and no accumulation in the young group, with significant correlations between creatinine clearance and clearance of anti-factor Xa activity. Interestingly, accumulation occurred in the elderly despite the fact that their mean creatinine clearance was not so low (mean $62 \pm 6 \mathrm{~mL} / \mathrm{min}$ vs $114 \pm 15 \mathrm{~mL} / \mathrm{min}$ in the young). ${ }^{60}$ If LMWH is prescribed at therapeutic dose in patients with renal insufficiency, anti-factor Xa monitoring and/or dose reduction should be considered. The anti-factor Xa activity should be measured 4 hours after a sc. injection (peak level). The usually accepted target range for anti-factor Xa activity is 0.6 to $1.0 \mathrm{IU} / \mathrm{mL}$ for twice-daily administration and 1.0 to $2.0 \mathrm{IU} / \mathrm{mL}$ for once daily administration. In case of severe renal insufficiency, UFH should be preferred to LMWH. ${ }^{9}$ Fondaparinux is contra-indicated in patients with creatinine clearance $<30 \mathrm{~mL} / \mathrm{min}$ at either prophylactic or therapeutic dosage. ${ }^{49} \mathrm{~A}$ suggested regimen for the use of parenteral anticoagulant in patients with renal insufficiency is presented in Table 6 .

\section{Comorbidities and risk of falls}

Several medical conditions are known to increase bleeding risk during VKA therapy, including hypertension, cerebrovascular disease, ischemic stroke, serious heart disease, diabetes, renal insufficiency, alcoholism and liver disease. ${ }^{47}$ Most of these conditions have a higher prevalence among elderly patients, and should be taken into account while estimating risk-benefit ratio of oral anticoagulation (see also bleeding scores above). 
Table 6 Suggested regimen for the use of parenteral anticoagulants in patients with renal insufficiency

\begin{tabular}{lll}
\hline $\begin{array}{l}\text { Creatinine clearance } \\
\text { (Cockroft) }\end{array}$ & Prophylactic anticoagulation & Therapeutic anticoagulation \\
\hline$>50 \mathrm{~mL} / \mathrm{min}$ & - Fondaparinux & - Fondaparinux \\
$30-50 \mathrm{~mL} / \mathrm{min}$ & - LMWH & - LMWH \\
& - LMWH without dose reduction & or 4th dose, anti-Xa monitoring twice weekly thereafter \\
& - Fondaparinux without dose & (NB dose reduction can be considered in this group if \\
& & creatinine clearance is at the lower limit) \\
& & - UFH \\
& & - Fondaparinux for limited duration of treatment (caution \\
& & in case of prolonged treatment because of the risk of \\
& accumulation)
\end{tabular}

Abbreviations: LMWH, low molecular weight heparins; UFH, unfractionated heparin.

Another major concern when prescribing VKA in elderly patients is the risk for falls. Gage et al showed an increased risk of intracranial hemorrhage ( $\mathrm{ICH})$ in patients with $\mathrm{AF}$ at high risk of falls (based on physician's documentation in patient's medical record: "frequent falls, history of falls, multiples falls, or tendency for falls") compared to other patients (2.8 versus 1.1 per 100 patient-years). ${ }^{61}$ Prescription of warfarin did not affect the incidence rate of ICH, but the severity of the hemorrhagic events with a higher 30-day mortality in patients on warfarin $(51.8 \%$ vs $33.6 \%$ for those without warfarin; $p=0.007$ ). Other independent risk factors for ICH in this study were prior stroke, prior major bleeding and neuropsychiatric impairment. Nevertheless, patients at high risk for falls and thus ICH were at even higher risk for ischemic stroke associated with AF (13.7 per 100 patientyears). Therefore, patients with $\mathrm{AF}$ with additional stroke risk factors seem to have an overall benefit from anticoagulation even if they are at high risk for falls. ${ }^{61}$

\section{Pharmacokinetics and pharmacodynamics of VKAs in the elderly}

Warfarin is a drug from the coumarin group and is the most widely used VKA worldwide. It is administered orally and rapidly absorbed from the gastrointestinal tract. It achieves its anticoagulant effect by interfering with vitamin K metabolism, thus reducing hemostatically active factors II, VII, IX and X. About $99 \%$ of warfarin is bound to plasma proteins and it is eliminated through metabolism by the liver cytochrome P450 CYP2C9. ${ }^{62,63}$ Factors influencing pharmacokinetics of warfarin are not age-specific. They include diminished absorption (eg, fat malabsorption, cholestyramine), enzyme genetic polymorphisms influencing hepatic metabolism, and specially drug interactions at the CYP2C9 level, which either can increase or decrease INR level. Drug interactions represent a significant issue in elderly patients on warfarin because of polymedication and frequent changes (adding or stopping) in concomitant medications related to intercurrent acute illnesses.

Elderly patients also show increased pharmacodynamic response to warfarin for several reasons: they may have decreased synthesis of clotting factors due to liver disease; their dietary vitamin $\mathrm{K}$ intake (contained mainly in leafy green vegetables) may be low, especially in acute medical settings, so there is less competitive antagonism to the effect of VKA; the level of vitamin K produced by intestinal bacteria may be decreased by broad-spectrum antibiotics; concomitant use of drugs interacting with platelet function including nonsteroidal anti-inflammatory drugs (NSAIDS) or aspirin is more frequent and increases bleeding risk; hypermetabolic states such as fever (probably through increased catabolism of vitamin K-dependant clotting factors) may increase response to warfarin in greater extent in frail elderly patients with poor vitamin K storage..$^{62,63}$

Because of this higher sensitivity to warfarin in the elderly, usual recommended initial doses of warfarin cannot be applied to this population. Garcia et al pointed out the effect of age and sex on warfarin response, and the risk of excessive anticoagulation when initiating warfarin 
in elderly ambulatory patients: if warfarin is initiated at $5 \mathrm{mg} /$ day, $82 \%$ of women and $65 \%$ of men aged $>70$ years will be overanticoagulated. The authors showed that for each year of age, the weekly required warfarin dose was reduced by $0.4 \mathrm{mg}$, and that at any given age, the weekly warfarin dose for women was $4.5 \mathrm{mg}$ lower than for men. ${ }^{64}$ A specific low-dose regimen has been developed for initiating warfarin therapy in medical inpatients $>70$ years and validated prospectively by Siguret et al. ${ }^{65}$ Mean age of the validation sample was $84.6 \pm 4.9$ and mean body weight $64 \pm 15 \mathrm{~kg}$. Maintenance dose was predicted depending on INR level measured on the fourth day, after three daily doses of $4 \mathrm{mg}$ of warfarin. The predicted maintenance dose of warfarin $(3.2 \pm 1.6 \mathrm{mg} /$ day $)$ correlated well with actual dose $(3.1 \pm 1.7 \mathrm{mg} /$ day $)$. Therefore, this proposed regimen could represent a useful tool for avoiding overanticoagulation when introducing warfarin in the elderly (Table 7).

In trying to start and maintain safe and stable anticoagulation with VKAs in the elderly, physicians should be aware of increased response to warfarin in this age group. Furthermore, physicians and patients should keep in mind potential major effects of dietary changes and drug interactions (even over-the-counter and herbal medicines) on anticoagulation intensity. INR should be closely monitored whenever changes occur in dietary habits or concomitant medications. ${ }^{62}$ Ideally, patient education about oral anticoagulation should be part of the therapy as it is the case for diabetic patients. Indeed, Kagansky et al identified poor quality of education as a major risk factor for anticoagulation-associated bleeding complications in the elderly. ${ }^{66}$

Table 7 Specific low-dose regimen for initiating warfarin therapy for patients $>70$ years ${ }^{65}$

\begin{tabular}{lll}
\hline Day & INR value I0 AM & Warfarin dose $(\mathbf{m g})$ 6 PM \\
\hline Day 0 & Do not measure & 4 \\
Day I & Do not measure & 4 \\
Day 2 & Do not measure & 4 \\
& & Predicted maintenance dose \\
Day 3 & $<1.3$ & 5 \\
& INR $\geq 1.3$ & 4 \\
& INR $\geq 1.5$ & 3 \\
& INR $\geq 1.7$ & 2 \\
& INR $\geq 1.9$ & I \\
& INR $\geq 2.5$ & Measure INR daily and omit doses \\
& & until INR $<2.5$ mg, then give I mg
\end{tabular}

Notes: This algorithm does not apply to patients who have received warfarin within the preceding week of have a pretreatment international normalized ratio $(\mathrm{INR})>1.3$.

\section{Association with antiplatelet agents}

Because of increased incidence of cardiovascular events with age, elderly patients are likely to have indications for both oral anticoagulation and antiplatelet therapy, the most typical situation being AF associated with ischemic heart disease. With the exception of some patients with prosthetic heart valves (see above), combination of anticoagulant and antiplatelet therapy has not been proven to be superior to anticoagulation alone for any other indication, and carries a significantly increased bleeding risk. ${ }^{67}$ There is persistent debate concerning patients on oral anticoagulation who suffer from an acute coronary syndrome necessitating percutaneous coronary intervention with stent implantations. Some authors believe that in this context, selected patients at high thromboembolic risk have an overall benefit of a triple therapy (aspirin and clopidogrel added to their usual anticoagulation regime), provided some precautions are observed: avoidance of drug eluting stents (complete endothelialisation of bare metal stents occurs much more rapidly, thus requiring dual antiplatelet therapy after stenting for one month compared to 6 months at least for drug eluting stents), avoidance of periprocedural glycoprotein IIb/IIa inhibitors whenever possible, increased frequency of INR monitoring during triple therapy, prescription of gastric protection. ${ }^{68}$

\section{Newer anticoagulant agents}

In contrast to the earlier described therapeutic agents, newer anticoagulants selectively target specific steps in the coagulation cascade. The farthest along in clinical development include agents targeting factor Xa and factor IIa (thrombin). Factor $\mathrm{Xa}$ is an attractive target as it is positioned at the start of the common pathway of coagulation. Thrombin plays a central role by converting fibrinogen to fibrin, and activating other coagulation factors (V, VII, XI, XIII) and platelets.

\section{Indirect $\mathrm{Xa}$ inhibitors}

Pentasaccharides represent the first generation of factor $\mathrm{Xa}$ inhibitors. These synthetic drugs (fondaparinux, idraparinux) selectively inhibit factor Xa through their binding to and activation of antithrombin and are therefore called indirect inhibitors. Their structure is based on the pentasaccharide region of the heparin molecule specific for antithrombin binding: they lack the longer saccharide chain that neutralizes thrombin. They are administered by subcutaneous injection. Unlike the heparins, the pentasaccharides bind selectively to antithrombin and do not affect platelet function or react with heparin-PF4 antibodies. Their use at prophylactic or therapeutic doses has been discussed hereabove. 


\section{Direct $\mathrm{Xa}$ inhibitors}

Based on the efficacy of fondaparinux, research is directed toward the development of oral drugs inhibiting factor Xa. These molecules reversibly block the active site of factor $\mathrm{Xa}$, without binding to antithrombin (direct inhibitors). This allows the inhibition within the assembled prothrombinase complex as well as the inhibition of free factor Xa. Two oral direct Xa inhibitors are currently ongoing phase III trials for treatment of VTE: apixaban and rivaroxaban. Phase II studies of apixaban for the treatment of DVT showed low recurrence and bleeding rates, warranting a phase III trial. The same conclusions were drawn in two phase II studies evaluating rivaroxaban, another oral inhibitor. ${ }^{69-71}$ These drugs appear very promising, as they possess two major advantages over the current anticoagulation therapies: there is no need for close monitoring of the anticoagulant effect, and they are administered orally from the beginning of the treatment. In the case of solid phase III results and absence of toxicity reports, they could supplant the initial treatment with LMWH/pentasaccharide and secondary phase with VKA.

\section{Direct thrombin inhibitors}

Another way to efficiently alter the coagulation system is through the direct inhibition of thrombin (factor IIa), independently of antithrombin. Current examples include hirudin and argatroban, parenteral drugs approved for the treatment of HIT. Proof of the efficiency of oral molecules was set by trials on the first oral thrombin inhibitor studied, ximelagatran. In 2005, the THRIVE investigators concluded on the non-inferiority of 6-month ximelagatran compared to enoxaparin followed by warfarin for proximal DVT. ${ }^{72}$ This drug also proved to be similar to standard anticoagulation in other settings: anticoagulation in orthopedic thromboprophylaxis, and stroke prevention in atrial fibrillation. This led to its temporary licensing in Europe, until it was eventually withdrawn from the world market because of potential hepatic toxicity. However, this provided proof that an oral anticoagulant with no need of monitoring could be as efficacious and safe in terms of major bleeding as LMWH followed by VKA after VTE. Currently, dabigatran is undergoing phase III trials for the initial and long-term treatment of VTE (RE-COVER, RE-MEDY trials). So far, its use has not been associated with hepatotoxicty.

The major advantages of this class are the same as of the oral direct Xa inhibitors: oral route and predictable anticoagulant response without need for coagulation monitoring. One drawback is the absence of antidote. Moreover, recombinant factor VIIa was shown to have a limited capacity to reverse the anticoagulant effect of melagatran. ${ }^{73}$ Overall, the safety and bleeding risk associated with these newer anticoagulants drugs in elderly patients will have to be studied in further trials.

\section{Conclusions}

Elderly people represent a patient population at high thromboembolic risk. However, conditions contributing to higher hemorrhagic risk are also more prevalent in this population. Thorough knowledge of recommended indications to anticoagulation and consideration of the importance of thromboembolic risk in this population is important since there is a tendency to underuse anticoagulants in the elderly. Assessing the benefit-risk ratio of anticoagulation is one of the most challenging issues in the individual elderly patient, patients at highest hemorrhagic risk often being those who would have the greatest benefit from anticoagulants, and some clinical rules represent useful tools in everyday clinical practice in this setting. Few guidelines on the use of anticoagulants specific for the geriatric patient population are available. A practical guideline had been issued by the American Geriatrics Society in 2002 based on the 2001 ACCP evidence-based guidelines. An update is likely to be published in the near future following the 2008 ACCP evidence-based guidelines to which we refer along our review. Elderly patients represent a considerable subset in trials on VTE prophylaxis and AF, so the results of these studies seem applicable to the geriatric population. However, population age in VTE treatment trials is often significantly lower, and further trials specifically considering elderly patients are needed. In the meantime, all anticoagulant agents can be used in the elderly provided some important specific considerations are taken into account in order to maximise the safety of this treatment.

\section{Disclosures}

None of the authors disclose conflicts of interest.

\section{References}

1. Go AS, Hylek EM, Phillips KA, et al. Prevalence of diagnosed atrial fibrillation in adults: national implications for rhythm management and stroke prevention: the AnTicoagulation and Risk Factors in Atrial Fibrillation (ATRIA) Study. JAMA. 2001;285(18):2370-2375.

2. Anderson FA Jr, Wheeler HB, Goldberg RJ, et al. A population-based perspective of the hospital incidence and case-fatality rates of deep vein thrombosis and pulmonary embolism. The Worcester DVT Study. Arch Intern Med. 1991;151(5):933-938.

3. Stein PD, Hull RD, Kayali F, Ghali WA, Alshab AK, Olson RE. Venous thromboembolism according to age: the impact of an aging population. Arch Intern Med. 2004;164(20):2260-2265.

4. Weill-Engerer S, Meaume S, Lahlou A, et al. Risk factors for deep vein thrombosis in inpatients aged 65 and older: a case-control multicenter study. J Am Geriatr Soc. 2004;52(8):1299-1304. 
5. Alikhan R, Cohen AT, Combe S, et al. Prevention of venous thromboembolism in medical patients with enoxaparin: a subgroup analysis of the MEDENOX study. Blood Coagul Fibrinolysis. 2003;14(4):341-346.

6. Di Minno G, Tufano A. Challenges in the prevention of venous thromboembolism in the elderly. $J$ Thromb Haemost. 2004;2(8): $1292-1298$

7. Brotman DJ, Jaffer AK. Prevention of venous thromboembolism in the geriatric patient. Cardiol Clin. 2008;26(2):221-234, vi.

8. Geerts WH, Bergqvist D, Pineo GF, et al. Prevention of venous thromboembolism: American College of Chest Physicians EvidenceBased Clinical Practice Guidelines (8th Edition). Chest. 2008;133 (6 Suppl):381S-453S.

9. Kearon C, Kahn SR, Agnelli G, Goldhaber S, Raskob GE, Comerota AJ. Antithrombotic therapy for venous thromboembolic disease: American College of Chest Physicians Evidence-Based Clinical Practice Guidelines (8th Edition). Chest. 2008;133(6 Suppl):454S-545S.

10. Levine MN, Hirsh J, Gent M, et al. Optimal duration of oral anticoagulant therapy: a randomized trial comparing four weeks with three months of warfarin in patients with proximal deep vein thrombosis. Thromb Haemost. 1995;74(2):606-611.

11. Schulman S, Rhedin AS, Lindmarker P, et al. A comparison of six weeks with six months of oral anticoagulant therapy after a first episode of venous thromboembolism. Duration of Anticoagulation Trial Study Group. N Engl J Med. 1995;332(25):1661-1665.

12. Schulman S, Granqvist S, Holmstrom M, et al. The duration of oral anticoagulant therapy after a second episode of venous thromboembolism. The Duration of Anticoagulation Trial Study Group. N Engl J Med. 1997;336(6):393-398.

13. Lee AY, Levine MN, Baker RI, et al. Low-molecular-weight heparin versus a coumarin for the prevention of recurrent venous thromboembolism in patients with cancer. $N$ Engl J Med. 2003;349(2):146-153.

14. Heit JA, Silverstein MD, Mohr DN, Petterson TM, O’Fallon WM, Melton LJ, 3rd. Risk factors for deep vein thrombosis and pulmonary embolism: a population-based case-control study. Arch Intern Med. 2000;160(6):809-815.

15. Prandoni $\mathrm{P}$, Lensing AW, Prins MH, et al. Residual venous thrombosis as a predictive factor of recurrent venous thromboembolism. Ann Intern Med. 2002;137(12):955-960.

16. Kearon C, Gent M, Hirsh J, et al. A comparison of three months of anticoagulation with extended anticoagulation for a first episode of idiopathic venous thromboembolism. $N$ Engl $J$ Med. 1999;340(12):901-907.

17. Palareti G, Cosmi B, Legnani C, et al. D-dimer testing to determine the duration of anticoagulation therapy. $N$ Engl J Med. 2006;355(17): $1780-1789$

18. Kearon C, Ginsberg JS, Kovacs MJ, et al. Comparison of low-intensity warfarin therapy with conventional-intensity warfarin therapy for longterm prevention of recurrent venous thromboembolism. $N$ Engl J Med. 2003;349(7):631-639.

19. Ridker PM. Long-term low-dose warfarin use is effective in the prevention of recurrent venous thromboembolism: yes. $J$ Thromb Haemost. 2004;2(7):1034-1037.

20. Wolf PA, Abbott RD, Kannel WB. Atrial fibrillation: a major contributor to stroke in the elderly. The Framingham Study. Arch Intern Med. 1987;147(9):1561-1564.

21. Risk factors for stroke and efficacy of antithrombotic therapy in atrial fibrillation. Analysis of pooled data from five randomized controlled trials. Arch Intern Med. 1994;154(13):1449-1457.

22. Fang MC, Go AS, Chang Y, Borowsky L, Pomernacki NK, Singer DE. Comparison of risk stratification schemes to predict thromboembolism in people with nonvalvular atrial fibrillation. $J$ Am Coll Cardiol. 2008;51(8):810-815.

23. Gage BF, Waterman AD, Shannon W, Boechler M, Rich MW, Radford MJ. Validation of clinical classification schemes for predicting stroke: results from the National Registry of Atrial Fibrillation. JAMA. 2001;285(22):2864-2870.
24. Singer DE, Albers GW, Dalen JE, et al. Antithrombotic therapy in atrial fibrillation: American College of Chest Physicians Evidence-Based Clinical Practice Guidelines (8th Edition). Chest. 2008;133(6 Suppl): 546S-592S.

25. Baudet EM, Puel V, McBride JT, et al. Long-term results of valve replacement with the St. Jude Medical prosthesis. J Thorac Cardiovasc Surg. 1995;109(5):858-870.

26. Salem DN, O'Gara PT, Madias C, Pauker SG. Valvular and structural heart disease: American College of Chest Physicians Evidence-Based Clinical Practice Guidelines (8th Edition). Chest. 2008;133(6 Suppl): 593S-629S

27. Samama MM, Cohen AT, Darmon JY, et al. A comparison of enoxaparin with placebo for the prevention of venous thromboembolism in acutely ill medical patients. Prophylaxis in Medical Patients with Enoxaparin Study Group. N Engl J Med. 1999;341(11):793-800.

28. Kleber FX, Witt C, Vogel G, Koppenhagen K, Schomaker U, Flosbach CW. Randomized comparison of enoxaparin with unfractionated heparin for the prevention of venous thromboembolism in medical patients with heart failure or severe respiratory disease. Am Heart $J$. 2003;145(4):614-621.

29. Leizorovicz A, Cohen AT, Turpie AG, Olsson CG, Vaitkus PT, Goldhaber SZ. Randomized, placebo-controlled trial of dalteparin for the prevention of venous thromboembolism in acutely ill medical patients. Circulation. 2004;110(7):874-879.

30. Kucher N, Leizorovicz A, Vaitkus PT, et al. Efficacy and safety of fixed low-dose dalteparin in preventing venous thromboembolism among obese or elderly hospitalized patients: a subgroup analysis of the PREVENT trial. Arch Intern Med. 2005;165(3):341-345.

31. Cohen AT, Davidson BL, Gallus AS, et al. Efficacy and safety of fondaparinux for the prevention of venous thromboembolism in older acute medical patients: randomised placebo controlled trial. $B M J$. 2006;332(7537):325-329

32. Lassen MR, Bauer KA, Eriksson BI, Turpie AG. Postoperative fondaparinux versus preoperative enoxaparin for prevention of venous thromboembolism in elective hip-replacement surgery: a randomised double-blind comparison. Lancet. 2002;359(9319):1715-1720.

33. Colwell CW, Hardwick ME. Thromboprophylaxis in elderly patients undergoing major orthopaedic surgery. Drugs Aging. 2008;25(7): $551-558$.

34. Turpie AG, Bauer KA, Eriksson BI, Lassen MR. Fondaparinux vs enoxaparin for the prevention of venous thromboembolism in major orthopedic surgery: a meta-analysis of 4 randomized double-blind studies. Arch Intern Med. 2002;162(16):1833-1840.

35. Bounameaux H, Perneger T. Fondaparinux: a new synthetic pentasaccharide for thrombosis prevention. Lancet. 2002;359(9319): 1710-1711.

36. Kearon C, Ginsberg JS, Julian JA, et al. Comparison of fixed-dose weight-adjusted unfractionated heparin and low-molecular-weight heparin for acute treatment of venous thromboembolism. JAMA. 2006;296(8):935-942.

37. van Dongen CJ, van den Belt AG, Prins MH, Lensing AW. Fixed dose subcutaneous low molecular weight heparins versus adjusted dose unfractionated heparin for venous thromboembolism. Cochrane Database Syst Rev. 2004(4):CD001100.

38. Buller HR, Davidson BL, Decousus H, et al. Fondaparinux or enoxaparin for the initial treatment of symptomatic deep venous thrombosis: a randomized trial. Ann Intern Med. 2004;140(11):867-873.

39. Buller HR, Davidson BL, Decousus H, et al. Subcutaneous fondaparinux versus intravenous unfractionated heparin in the initial treatment of pulmonary embolism. N Engl J Med. 2003;349(18):1695-1702.

40. Warkentin TE, Maurer BT, Aster RH. Heparin-induced thrombocytopenia associated with fondaparinux. N Engl J Med. 2007;356(25):2653-2655; discussion 2653-2655.

41. Savi P, Chong BH, Greinacher A, et al. Effect of fondaparinux on platelet activation in the presence of heparin-dependent antibodies: a blinded comparative multicenter study with unfractionated heparin. Blood. 2005;105(1):139-144. 
42. Kuo KH, Kovacs MJ. Fondaparinux: a potential new therapy for HIT Hematology. 2005;10(4):271-275.

43. Kishimoto TK, Viswanathan K, Ganguly T, et al. Contaminated heparin associated with adverse clinical events and activation of the contact system. N Engl J Med. 2008;358(23):2457-2467.

44. Bijsterveld NR, Moons AH, Boekholdt SM, et al. Ability of recombinant factor VIIa to reverse the anticoagulant effect of the pentasaccharide fondaparinux in healthy volunteers. Circulation. 2002;106(20): 2550-2554.

45. Buller HR, Cohen AT, Davidson B, et al. Idraparinux versus standard therapy for venous thromboembolic disease. $N$ Engl $J$ Med. 2007;357(11):1094-1104.

46. Mant J, Hobbs FD, Fletcher K, et al. Warfarin versus aspirin for stroke prevention in an elderly community population with atrial fibrillation (the Birmingham Atrial Fibrillation Treatment of the Aged Study, BAFTA): a randomised controlled trial. Lancet. 2007;370(9586):493-503.

47. Schulman S, Beyth RJ, Kearon C, Levine MN. Hemorrhagic complications of anticoagulant and thrombolytic treatment: American College of Chest Physicians Evidence-Based Clinical Practice Guidelines (8th Edition). Chest. 2008;133(6 Suppl):257S-298S.

48. Campbell NR, Hull RD, Brant R, Hogan DB, Pineo GF, Raskob GE. Aging and heparin-related bleeding. Arch Intern Med. 1996;156(8):857-860.

49. Hirsh J, Bauer KA, Donati MB, Gould M, Samama MM, Weitz JI Parenteral anticoagulants: American College of Chest Physicians Evidence-Based Clinical Practice Guidelines (8th Edition). Chest. 2008;133(6 Suppl):141S-159S.

50. Fang MC, Go AS, Hylek EM, et al. Age and the risk of warfarinassociated hemorrhage: the anticoagulation and risk factors in atrial fibrillation study. J Am Geriatr Soc. 2006;54(8):1231-1236.

51. Palareti G, Hirsh J, Legnani C, et al.Oral anticoagulation treatment in the elderly: a nested, prospective, case-control study. Arch Intern Med. 2000;160(4):470-478.

52. Hylek EM, Evans-Molina C, Shea C, Henault LE, Regan S. Major hemorrhage and tolerability of warfarin in the first year of therapy among elderly patients with atrial fibrillation. Circulation. 2007;115(21):2689-2696.

53. Ruiz-Gimenez N, Suarez C, Gonzalez R, et al. Predictive variables for major bleeding events in patients presenting with documented acute venous thromboembolism. Findings from the RIETE Registry. Thromb Haemost. 2008;100(1):26-31.

54. Fang MC, Chang Y, Hylek EM, et al. Advanced age, anticoagulation intensity, and risk for intracranial hemorrhage among patients taking warfarin for atrial fibrillation. Ann Intern Med. 2004;141(10):745-752.

55. Man-Son-Hing M, Laupacis A. Anticoagulant-related bleeding in older persons with atrial fibrillation: physicians' fears often unfounded. Arch Intern Med. 2003;163(13):1580-1586.

56. Gage BF, Yan Y, Milligan PE, et al. Clinical classification schemes for predicting hemorrhage: results from the National Registry of Atrial Fibrillation (NRAF). Am Heart J. 2006;151(3):713-719.

57. Shireman TI, Mahnken JD, Howard PA, Kresowik TF, Hou Q, Ellerbeck EF. Development of a contemporary bleeding risk model for elderly warfarin recipients. Chest. 2006;130(5):1390-1396.

58. Nagge J, Crowther M, Hirsh J. Is impaired renal function a contraindication to the use of low-molecular-weight heparin? Arch Intern Med. 2002;162(22):2605-2609.

59. Mahe I, Gouin-Thibault I, Drouet L, et al. Elderly medical patients treated with prophylactic dosages of enoxaparin: influence of renal function on anti-Xa activity level. Drugs Aging. 2007;24(1):63-71.
60. Mismetti P, Laporte-Simitsidis S, Navarro C, et al. Aging and venous thromboembolism influence the pharmacodynamics of the anti-factor $\mathrm{Xa}$ and anti-thrombin activities of a low molecular weight heparin (nadroparin). Thromb Haemost. 1998;79(6):1162-1165.

61. Gage BF, Birman-Deych E, Kerzner R, Radford MJ, Nilasena DS, Rich MW. Incidence of intracranial hemorrhage in patients with atrial fibrillation who are prone to fall. Am J Med. 2005;118(6):612-617.

62. Ansell J, Hirsh J, Hylek E, Jacobson A, Crowther M, Palareti G. Pharmacology and management of the vitamin $\mathrm{K}$ antagonists: American College of Chest Physicians Evidence-Based Clinical Practice Guidelines (8th Edition). Chest. 2008;133(6 Suppl):160S-198S.

63. Jacobs LG. Warfarin pharmacology, clinical management, and evaluation of hemorrhagic risk for the elderly. Cardiol Clin. 2008; 26(2): 157-167, v.

64. Garcia D, Regan S, Crowther M, Hughes RA, Hylek EM. Warfarin maintenance dosing patterns in clinical practice: implications for safer anticoagulation in the elderly population. Chest. 2005;127(6): 2049-2056.

65. Siguret V, Gouin I, Debray M, et al. Initiation of warfarin therapy in elderly medical inpatients: a safe and accurate regimen. Am J Med. 2005;118(2):137-142.

66. Kagansky N, Knobler H, Rimon E, Ozer Z, Levy S. Safety of anticoagulation therapy in well-informed older patients. Arch Intern Med. 2004;164(18):2044-2050.

67. Eikelboom JW, Hirsh J. Combined antiplatelet and anticoagulant therapy: clinical benefits and risks. J Thromb Haemost. 2007;5 Suppl $1: 255-263$.

68. Rubboli A, Halperin JL. Pro: 'Antithrombotic therapy with warfarin, aspirin and clopidogrel is the recommended regime in anticoagulated patients who present with an acute coronary syndrome and/or undergo percutaneous coronary interventions'. Thromb Haemost. 2008;100(5):752-753.

69. Buller H, Deitchman D, Prins M, Segers A. Efficacy and safety of the oral direct factor Xa inhibitor apixaban for symptomatic deep vein thrombosis. The Botticelli DVT dose-ranging study. J Thromb Haemost. 2008;6(8):1313-1318.

70. Agnelli G, Gallus A, Goldhaber SZ, et al. Treatment of proximal deep-vein thrombosis with the oral direct factor Xa inhibitor rivaroxaban (BAY 59-7939): the ODIXa-DVT (Oral Direct Factor Xa Inhibitor BAY 59-7939 in Patients With Acute Symptomatic Deep-Vein Thrombosis) study. Circulation. 2007;116(2):180-187.

71. Buller HR, Lensing AW, Prins MH, et al. A dose-ranging study evaluating once-daily oral administration of the factor Xa inhibitor rivaroxaban in the treatment of patients with acute symptomatic deep vein thrombosis: the Einstein-DVT Dose-Ranging Study. Blood. 2008;112(6):2242-2247.

72. Fiessinger JN, Huisman MV, Davidson BL, et al. Ximelagatran vs low-molecular-weight heparin and warfarin for the treatment of deep vein thrombosis: a randomized trial. JAMA. 2005;293(6):681-689.

73. Wolzt M, Levi M, Sarich TC, et al. Effect of recombinant factor VIIa on melagatran-induced inhibition of thrombin generation and platelet activation in healthy volunteers. Thromb Haemost. 2004;91(6): 1090-1096.

74. Guyatt GH, Cook DJ, Jaeschke R, Pauker SG, Schunemann HJ. Grades of recommendation for antithrombotic agents: American College of Chest Physicians Evidence-Based Clinical Practice Guidelines (8th Edition). Chest. 2008;133(6 Suppl):123S-131S. 
